\title{
Task Prioritization Factors: Two Part-Task Simulator Studies
}

\author{
Kurt Colvin \\ IME Department \\ Cal Poly, San Luis Obispo \\ Ken Funk \\ IME Department \\ Oregon State University \\ Rolf Braune \\ Braune \& Associates, Inc. \\ Redmond, Washington
}

\begin{abstract}
Cockpit task management (CTM) is the initiation, monitoring, prioritization, execution, and termination of multiple, concurrent tasks by flight crews. In this research, we used 2 part-task simulator studies to elicit from pilots the factors actually used in task prioritization. Analysis resulted in the identification of 12 specific factors that the pilots reported as affecting task prioritization. From the results of these and related studies, we developed a hypothetical framework and model of task prioritization in which procedural consistency, importance to flight safety, and the salience of task-related stimuli are the primary factors that affect task prioritization.
\end{abstract}

On December 29, 1972, an Eastern Airlines Lockheed L-1011 was on final approach to Miami International Airport when a nose landing gear position indication light failed to illuminate. Following the missed approach because of a suspected nose gear malfunction, the aircraft climbed to 2,000 ft., leveled, and proceeded on a westerly heading. The three flight crew members and a jump seat occupant became engrossed in the malfunction. Several minutes later, the aircraft descended into the

Requests for reprints should be sent to Kurt Colvin, IME Department, California Polytechnic State University, San Luis Obispo, CA 93407. Email: kcolvin@calpoly.edu 
ground 18.7 miles west-northwest of the airport. The aircraft was destroyed. Of the 176 people aboard, 101 received fatal injuries. The accident report states the following (National Transportation Safety Board, 1973):

The National Transportation Safety Board determines that the probable cause of this accident was the failure of the flightcrew to monitor the flight instruments during the final 4 minutes of flight, [italics added] and to detect an unexpected descent soon enough to prevent impact with the ground. Preoccupation with a malfunction of the nose landing gear position indicating system distracted the crew's attention [italics added] from the instruments and allowed the descent to go unnoticed. (p. 22)

The cockpit is an environment in which potentially many important tasks simultaneously compete for pilot attention. Cockpit task management (CTM) is the initiation, monitoring, prioritization, execution, and termination of multiple, concurrent tasks by flight crews. It is the process by which pilots selectively attend to tasks in an effort to safely and effectively complete the mission. CTM entails initiation of new tasks and monitoring of ongoing tasks to determine their status; prioritization of tasks based on their importance, status, urgency, and other factors; allocation of human and machine resources to higher priority tasks; interruption and subsequent resumption of lower priority tasks; and termination of tasks that are completed or no longer relevant (Funk, 1991).

CTM is not new; in fact, pilots have always done it. CTM is a cognitive function that is intuitively well understood by pilots and almost always performed satisfactorily. However, there are many documented instances in which tasks were not managed properly, resulting in an aircraft incident or accident (Chou, Madhavan, \& Funk, 1996). Often, during critical phases of flight, this form of human error results in minor regulations violations or unsafe conditions that are rectified before a more serious situation develops. However, the consequences of improper CTM can be a catastrophic event with an aircraft hull loss and many deaths.

\section{RESEARCH QUESTION}

An element of CTM, and one of the topics related to multiple task performance that often arises in the human performance literature, is that of the prioritization of tasks: the conscious or unconscious process by which attention is directed toward a task (or a small number of tasks) and away from others. Gopher (1992) postulated that attention strategies can be defined as a vector of factors. Logan (1985) suggested two factors, cue validity and resource requirements, that affect task prioritization. Adams and Pew (1990) asked "What are the factors that determine when the human operator will shift attention to any particular task in the task queue?" Stated very simply, the question we posed in this research was what are the factors that affect task prioritization in the CTM process? 
The literature has provided a few very tentative answers to this question. For example, Pashler (1998) suggested that knowledge of upcoming tasks, the discriminability of task-related stimuli, and differences in the level of effort required to process task-related stimuli affect the allocation of attention among tasks. Schutte and Trujillo (1996) asserted that pilots' long-held ordering of aviate $>$ navigate $>$ communicate $>$ manage systems tasks in fact strongly influences task prioritization.

\section{STUDY 1}

The objective of our first study of task prioritization factors was simply to identify the factors. Although we considered such factors as listed previously, we essentially started with a clean sheet. We designed the study to let pilots describe, in their own words, what factors are used. We created part-task simulator scenarios with challenging task management situations that required the participants to make task management decisions and then asked them to explain those decisions.

\section{Methodology}

Participants. The participants for this study were 8 airline pilots, all male, with an average of 7,472.5 total flying hours. They had an average of $984.4 \mathrm{hr}$ of single pilot time and $666.9 \mathrm{hr}$ of electronic flight instrument system (EFIS) experience. Their age range was 25 to 44 years, with an average of 35.6 years. They were recruited on a volunteer basis and were not compensated in any way.

Equipment. The part-task simulator was the National Aeronautics and Space Administration (NASA) Stone-Soup Simulator Version 4.1 developed at the NASA Ames Research Center. The simulator models a generic, twin-engine turbojet transport with an advanced autoflight system, similar to the aircraft the participants fly on a daily basis. The participant's interface consists of a primary flight display, horizontal situation indicator, mode control panel, engine indication and crew alerting system, navigation and communication radio interfaces, and other system displays and controls (see Figure 1). The hardware consisted of two SGI Indigo2 workstations (Silicon Graphics, Inc., Mountain View, CA) running the IRIX 6.2 operating system (Silicon Graphics, Inc., Mountain View, CA). Video equipment included camcorder, video monitor, and video mixer to obtain a picture-in-picture configuration. Video from the pilot's workstation was collected using an SGI Galileo Video board and software for video output. Audio equipment included a cassette recorder to record pilot interviews. 


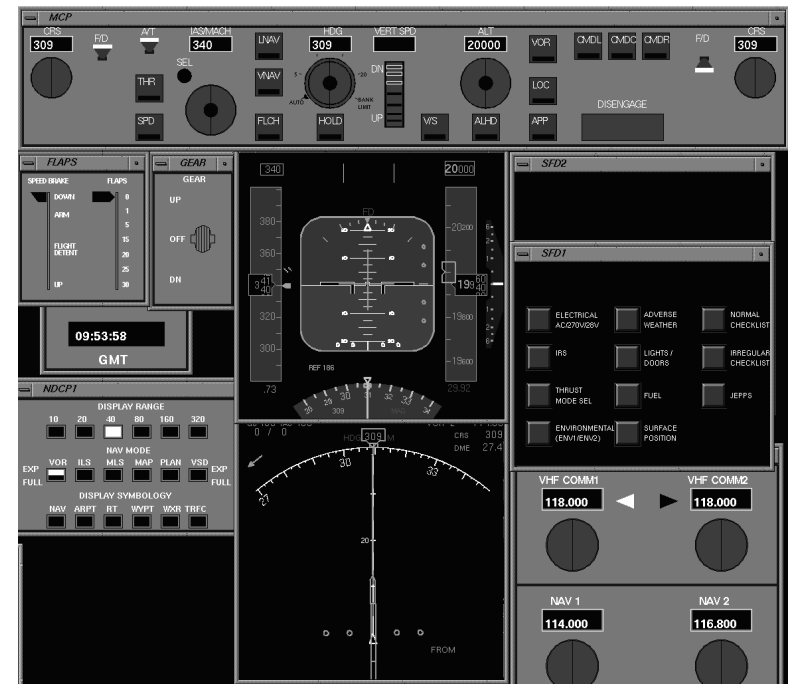

FIGURE 1 Screen shot of the National Aeronautic and Space Administration Stone-Soup Simulator, used for both studies.

Experimental design. The experiment consisted of two flight scenarios, both built around instrument approaches to San Francisco International Airport (SFO). The "Bravo" scenario is shown in Figure 2. The "Sierra" scenario was very similar yet different enough so that the pilots could not anticipate air traffic control (ATC) clearances for headings, altitudes and airspeeds, or timing and type of equipment malfunction events. Each participant flew both scenarios, which were videotaped in their entirety.

Each scenario contained six events that required the participant to selectively attend to a set of several concurrent tasks. In each scenario, there were two flight plan events (e.g., turns), two ATC events (ATC calls, with the experimenter [K. Colvin] acting as air traffic controller), and two malfunction events (equipment failures triggered by the experimenter). Either before or after each event, the experimenter probed the participant to determine what factors were influencing the task prioritization process using an intrusive or a retrospective method (e.g., Cooke, 1994; Salter, 1988). In the intrusive method, the experimenter paused the simulator and administered the probe using the cognitive interview technique developed by Fisher and Geiselman (1992). After the probe, the experimenter resumed the simulation until the next event. In the retrospective method, the scenario was flown without interruption, and the experimenter conducted the probe by reviewing the videotape with the participant.

For both methods, we began each probe in a structured manner and asked specific questions about what tasks the pilot was performing at the time of the probe. 
The first part of the probe was to establish the task currently attended, the task that was to be attended to next, and a list of remaining tasks that were currently active in the pilots memory. Following this identification of the pilot's current task list, the experimenter posed a series of questions that probed why the current task had a higher priority than the other tasks listed. It was during this portion of the probe that we used cognitive interview techniques to retrieve as much insightful and detailed information from the pilot as possible as to what factors influenced the prioritization of tasks. We audiotaped each probe for later analysis.

Following are excerpts of the initial portion of the probe dialog:

1. What task are you attending to right now?

2. What other tasks are waiting to be performed? ...

Study 1 Bravo Experimental Scenario with Data Collection Points

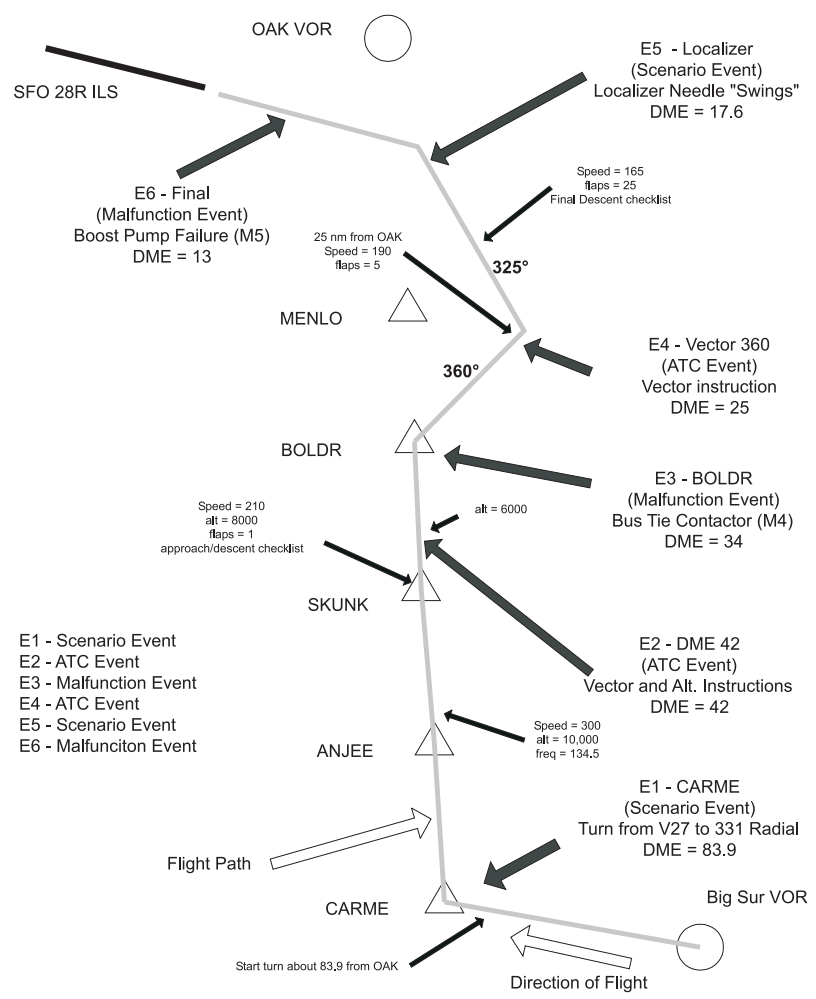

FIGURE 2 Study 1 "Bravo" scenario. OAK = Oakland International Airport; VOR = very high frequency omnidirectional range; $\mathrm{SFO}=\mathrm{San}$ Francisco International Airport; ILS = instrument landing system; $\mathrm{DME}=$ distance measuring equipment; $\mathrm{ATC}=$ air traffic control. 
3. Why was it that you were attending to $<$ the current task $>$ instead of $<$ the next task $>$ ? ... [Pause]

4. You mentioned $<$ factor $l>$ as one of the reasons you were attending to $<$ the current task $>$. Tell me more about $<$ Factor $1>$ [Pause]. Is this something usual for you, or is this a special situation? [Pause] Why? [Pause] Is there anything else you can tell me about $<$ Factor $1>$ ?

5. What task will you attend to next?

6. [The experimenter then repeated Steps 2 through 6 for each task and factor.]

Our knowledge elicitation techniques required the pilots to identify a very specific order in which they performed tasks. We acknowledge that expert pilots may have the ability to perform multiple, concurrent tasks, and we do not attempt to refute that point in this work. However, for these studies, we assumed that there was a strict prioritization of tasks, with a single task that emerged as the most prominent task and occupied a significant amount of the pilot's attention. This assumption is in agreement with the general consensus (see, e.g., Adams, Tenny, \& Pew, 1991; Gopher, 1992; Logan, 1985) that a human can perform but one cognitively difficult task at a time- and these tasks were designed to be challenging.

The experimental design was a $2 \times 2 \times 2$ factorial design, and all factors were fully counterbalanced between participants. The treatments were scenario order (Bravo and Sierra), elicitation technique (retrospective and intrusive), and probe timing (before event and after event).

\section{Results}

The cognitive interviews of the pilots resulted in approximately $7 \mathrm{hr}$ of audiotape. Although the interviews resulted in a large set of data, we present just data relevant to the identification of prioritization factors (Question 3 from the preceding list). In multiple replays by a single experimenter, the pilots' responses were placed into 1 of 12 categories. These categories (or factors) were not predetermined but were a result of naturally occurring divisions of the responses. We made every attempt to classify the pilots' responses according only to what was said during the probe. In other words, in the analysis, we classified what the pilot actually verbalized and did not attempt to infer beyond what the pilots said. Table 1 presents the 12 factors and representative quotations from the participants. Figure 3 presents the overall tally of reported factors. Factors with low frequencies simply were not reported by many of the participants in the probing interviews.

Analysis of variance (ANOVA) showed no effect of scenario $(p=.82)$, elicitation technique ( $p=.96)$, or probe timing $(p=.29)$ on factor reporting frequencies. That is, frequencies appeared consistent across all experimental conditions. Clearly, status and procedure emerged as the most frequently reported factors. 
TABLE 1

Factors That Affect Task Prioritization Reported by Pilots

\begin{tabular}{|c|c|c|}
\hline Factor & Description & Representative Quotation \\
\hline Procedure & $\begin{array}{l}\text { The appropriate (according to the pilot) } \\
\text { task to execute in this situation; an } \\
\text { environmental cue prompted this } \\
\text { task; in this situation, the task is } \\
\text { always performed }\end{array}$ & $\begin{array}{l}\text { "When I arrived at the waypoint, I } \\
\text { initiated a turn because it was the } \\
\text { appropriate thing to do [i.e, } \\
\text { consistent with the published } \\
\text { approach procedure]." }\end{array}$ \\
\hline Status & $\begin{array}{l}\text { Current task status-how near to } \\
\text { completion or how well it was being } \\
\text { performed-affected the } \\
\text { prioritization of the task }\end{array}$ & $\begin{array}{l}\text { "My altitude was } 100 \text { ' feet low and I } \\
\text { was still descending. I had to get my } \\
\text { altitude back before I could do } \\
\text { anything else." }\end{array}$ \\
\hline $\begin{array}{l}\text { Rate of } \\
\text { change }\end{array}$ & $\begin{array}{l}\text { The rate of change or trend of the task } \\
\text { status affected the prioritization of } \\
\text { the task }\end{array}$ & $\begin{array}{l}\text { "I was currently turning to a heading of } \\
360 \text {, and I knew that if I looked } \\
\text { away, I would overshoot my desired } \\
\text { heading." }\end{array}$ \\
\hline $\begin{array}{l}\text { Needed } \\
\quad \text { information }\end{array}$ & $\begin{array}{l}\text { The task was the source of needed } \\
\text { information }\end{array}$ & $\begin{array}{l}\text { "I was attending to the navigational } \\
\text { display because it had the } \\
\text { information (DME distance) I } \\
\text { needed at the time." }\end{array}$ \\
\hline Urgency & $\begin{array}{l}\text { There was a time pressure to perform } \\
\text { the task }\end{array}$ & $\begin{array}{l}\text { "I would be intercepting the localizer } \\
\text { very soon, so I needed to configure } \\
\text { the instruments for the ILS." }\end{array}$ \\
\hline Importance & $\begin{array}{l}\text { The task was more important than the } \\
\text { other tasks }\end{array}$ & $\begin{array}{l}\text { "On final approach, tracking the ILS is } \\
\text { the most important task." }\end{array}$ \\
\hline $\begin{array}{l}\text { Verifying } \\
\text { information }\end{array}$ & $\begin{array}{l}\text { The task was being performed to } \\
\text { cross-check and verify other task } \\
\text { status information. }\end{array}$ & $\begin{array}{l}\text { "After leveling the wings (using the } \\
\text { ADI), I checked the navigational } \\
\text { display to verify I was on the correct } \\
\text { heading." }\end{array}$ \\
\hline $\begin{array}{l}\text { Time/effort } \\
\text { required }\end{array}$ & $\begin{array}{l}\text { The time/effort to perform task was } \\
\text { small (or large), which affected } \\
\text { prioritization of the task }\end{array}$ & $\begin{array}{l}\text { "I replied to ATC first, because it was } \\
\text { quick and easy." }\end{array}$ \\
\hline $\begin{array}{l}\text { Salience of } \\
\text { display }\end{array}$ & $\begin{array}{l}\text { The salience of the display prompted } \\
\text { that the task be performed }\end{array}$ & $\begin{array}{l}\text { "The caution lights caught my } \\
\text { attention, so I fixed the problems } \\
\text { before returning to the checklist." }\end{array}$ \\
\hline Consequences & $\begin{array}{l}\text { The consequences of not performing } \\
\text { the task were great; the task has } \\
\text { safety implications if it were not } \\
\text { performed }\end{array}$ & $\begin{array}{l}\text { "If I didn't initiate a turn, I would be in } \\
\text { violation of ATC instructions and it } \\
\text { could be a safety consideration with } \\
\text { other aircraft or terrain." }\end{array}$ \\
\hline $\begin{array}{l}\text { Resist } \\
\text { forgetting }\end{array}$ & $\begin{array}{l}\text { The task was performed immediately } \\
\text { to resist the tendency to forget the } \\
\text { goal }\end{array}$ & $\begin{array}{l}\text { "When ATC gives me an altitude, I } \\
\text { immediately input the altitude into } \\
\text { the panel so I don't forget the } \\
\text { number." }\end{array}$ \\
\hline Expectancy & $\begin{array}{l}\text { The task was performed with an } \\
\text { expectancy of upcoming events }\end{array}$ & $\begin{array}{l}\text { "I was looking for things to do now, so } \\
\text { I would have less to do when it got } \\
\text { busy." }\end{array}$ \\
\hline
\end{tabular}

Note. $\quad \mathrm{DME}=$ distance measuring equipment; $\mathrm{ILS}=$ instrument landing system; $\mathrm{ADI}=$ attitude director indicator; $\mathrm{ATC}=$ air traffic control. 


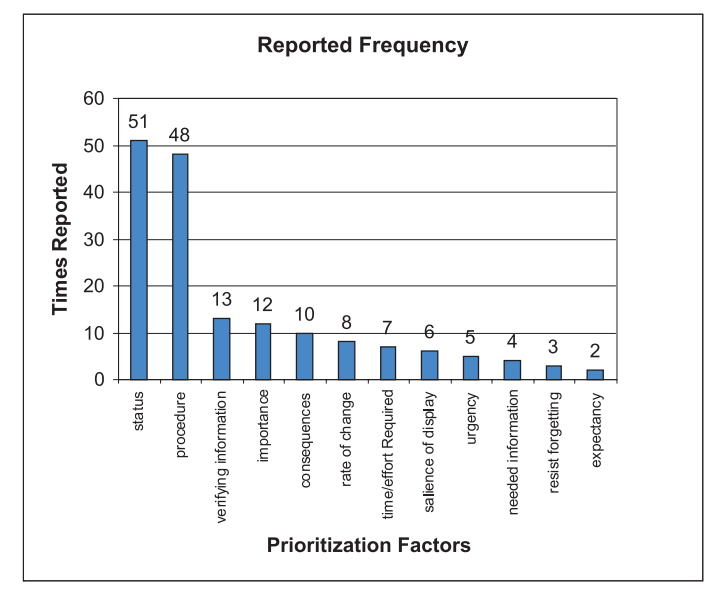

FIGURE 3 Overall reported tally of factors that affect task prioritization.

\section{Discussion}

Using the results, we attempted to distill the factors into a more concise subset. This process involved analyzing the relations between factors to identify common characteristics. For example, we recorded the Importance of a Task and Consequence of Not Performing the Task as separate factors, but they are, in a pilot's perspective, very similar. To a pilot, a task is important if failing to perform it jeopardizes the safety of the aircraft or passengers, violates Federal Aviation Administration regulations, or fails to comply with ATC clearances. Although pilots verbally differentiated between importance and consequences, we simply called this combined factor Importance. We directed similar efforts toward the other 10 factors, which ultimately resulted in a subset of 6 factors: Status, Procedure, Importance, Time/Effort, Urgency, and Salience. This subset of factors was used as the basis for Study 2. Full details of these reduction efforts are presented in Colvin (2000). We explain and justify other factor relations in the presentation of the model, which follows our findings (see following).

\section{STUDY 2}

The objective of the second study was to further investigate the pilots' use of a subset of prioritization factors we identified in the first study. The factors in this subset (Status, Procedure, Importance, Time/Effort, Urgency, and Salience) 
were established by reduction efforts on the initial 12 factors we reported in Study 1 (see previous discussion). In addition, we collected and analyzed task performance data with the objective of identifying a relation between task performance and prioritization factors used by pilots.

\section{Methodology}

The participants for this study were 8 airline pilots, all male, with an average of 6,838 total flying hours. They had an average of 2,531 hr of single pilot time and $481 \mathrm{hr}$ of EFIS experience. Their age range was 25 to 52 years, with an average of 34.6 years. As the experiment was conducted at a location remote from their domicile, we paid them a stipend and travel expenses for their participation in the study.

The equipment for this study was identical to that of the first, but we changed the flight scenarios to emphasize the low altitude circumstances of the final approach phase of flight in an attempt to increase the criticality of misprioritizing tasks.

Data collection for the experiment consisted of four flight scenarios, all variations of the same arrival scenario, with the differences existing in the challenge probe point (CPP) of a particular scenario. A CPP was an operational situation during the scenario where up to six tasks could become active at the same instant. The pilot had to prioritize and perform the tasks. For example, in Scenario A (Figure 4), the CPP was located at the SUNOL intersection and was the focus of data collection for this scenario. At SUNOL, an ATC call was initiated, giving a speed clearance. In addition, an engine fire was initiated that required the pilot to perform an engine fire checklist. The participant was faced with the following six concurrent tasks:

1. Initiate a descent to $4000 \mathrm{ft}$.

2. Initiate a turn to a heading of $240^{\circ}$.

3. Respond to an ATC clearance to reduce speed to 180 knots (kt).

4. Reduce the aircraft's speed to $180 \mathrm{kt}$.

5. Perform the engine fire checklist.

6. Configure the displays for the instrument landing system (ILS).

At each CPP, all six tasks were probed for the extent to which each of six factors affected the order in which the tasks were performed. We used the retrospective interviewing technique in coordination with a structured questionnaire. We selected this technique for its low intrusiveness, ease of application, and because in Study 1 , we found that no statistically significant differences existed between results from the intrusive and retrospective techniques. For example, while reviewing the 


\section{Challenge Probe Point A: Engine Fire at SUNOL}

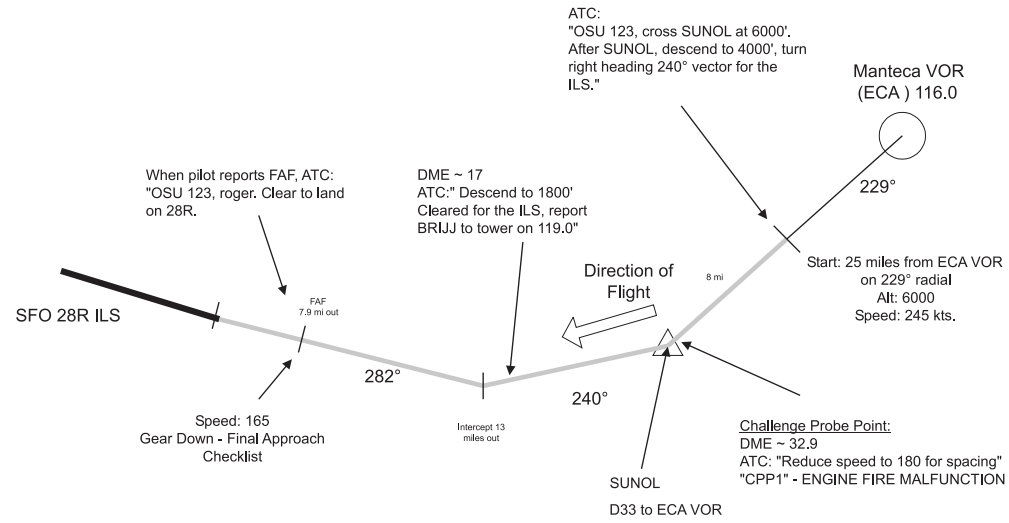

FIGURE 4 Study 2, Scenario A, with engine fire event at SUNOL. ATC = air traffic control; $\mathrm{VOR}=$ very high frequency omnidirectional range $\mathrm{FAF}=$ final approach fix; DME = distance measuring equipment; ILS = instrument landing system; SFO = San Francisco International Airport; $\mathrm{CPP} 1=$ critical point position 1 .

CPP in the videotape for Scenario A, the experimenter asked the participant to respond to the following assertions:

I initiated the turn to 240 when I did because I judged it to be the task farthest from satisfactory completion.

The reason I performed the engine fire checklist when I did was because the master warning light and EICAS message area caught my attention.

At each CPP, the participant responded to 18 such assertions (six task prioritization factors for each of three tasks: a navigate, communicate, and manage systems task) by choosing from a Likert scale ranging from +2 (strongly agree),+1 (agree), 0 (not applicable), -1 (disagree), to -2 (strongly disagree).

\section{Results}

We analyzed the questionnaire responses using analysis of variance (ANOVA). The experimental design was a fixed effect model having six levels (Status, Procedure, Importance, Time/Effort, Urgency, and Salience). The main effect of task prioritization factors was significant, $F(5,35)=5.14, p<.01$. Figure 5 presents the results, with the height of each bar representing the level of agreement that the corresponding factor influenced task sequencing, averaged across partic- 
ipants across all runs. Figure 5 is in effect a composite task prioritization "vector" showing the extent to which each of the factors affected task prioritization. Over the entire experiment, Procedure emerged as the factor most agreed to by pilots for use in task prioritization, followed in descending order by Salience, Importance, Time/Effort, Urgency, and finally Status.

However, there were differences among individual task prioritization vectors. Figure 6 is the task prioritization vector of the worst performer, the participant who committed the most errors (two altitude deviations and failure to perform a fuel cross-feed task). Figure 7 is the task prioritization vector of the best performer who committed no errors. An ANOVA revealed that overall, participants' vectors were significantly different, $F(7,240)=4.53, p<.001$. However, an ANOVA across all participants showed no statistically significant difference between the prioritization vectors obtained from runs in which errors were committed and those in which no errors were committed. That is, "faulty" task prioritization vectors alone could not account for these errors.

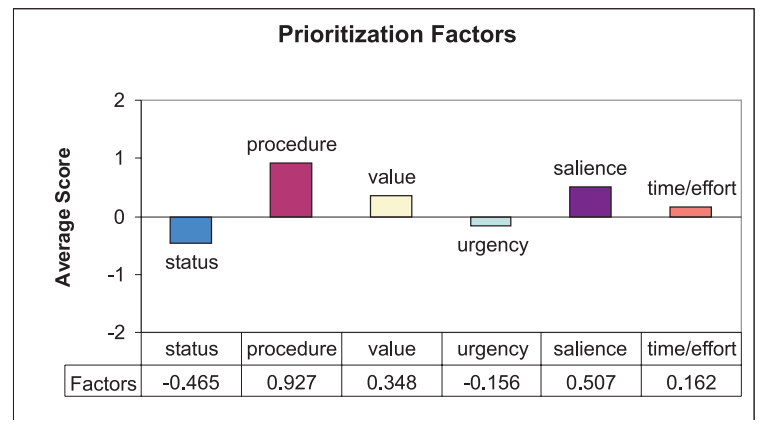

FIGURE 5 Reported effect of factors on task prioritization averaged over all participants.

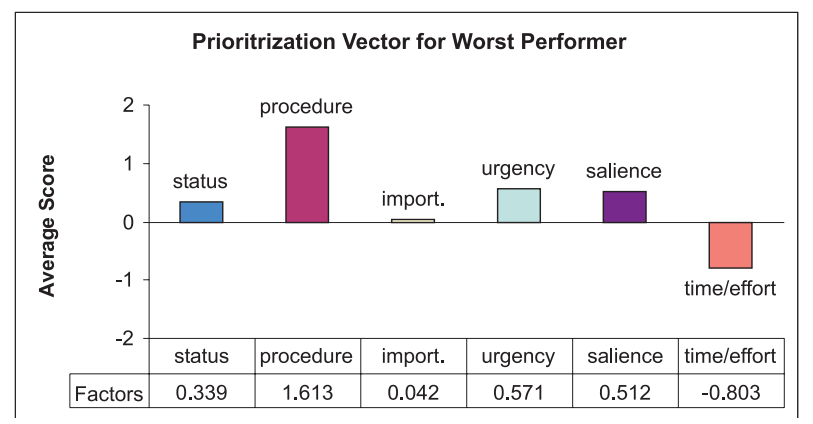

FIGURE 6 Task prioritization vector for worst performing participant. 


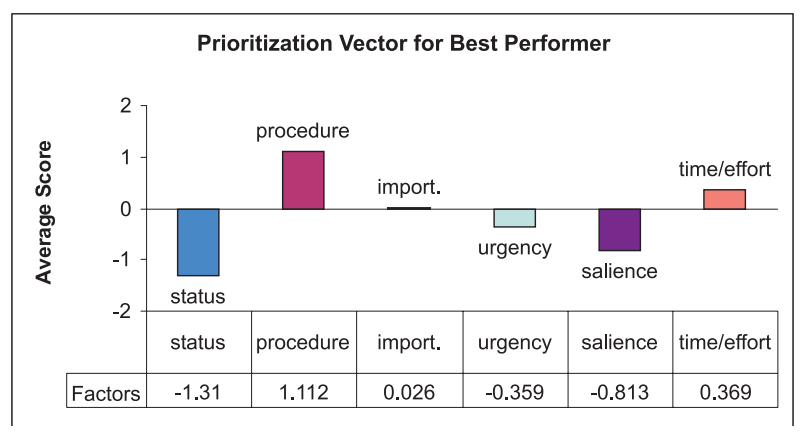

FIGURE 7 Task prioritization vector for best performing participant.

\section{Discussion}

One of the primary findings in this study was the individual difference pilots exhibited in the task prioritization process. This is consistent with the findings of Schutte and Trujillo (1996) in which they concluded general CTM was largely dependent on individual differences. This suggests that there is no general prioritization vector for all pilots that has been hypothesized by others (e.g., Adams \& Pew, 1990; Gopher, 1992; Logan, 1985). However, with these results, it does appear that certain factors emerge as prominent in affecting task prioritization.

Procedure is perhaps the most influential factor. This is not entirely surprising, as flying an aircraft is highly procedural and current training programs reflect this in their procedure-based philosophies.

We found Importance to have more influence in task prioritization than was suggested by the previous study. This is reassuring, as one reasonable strategy to perform the tasks would be to always perform the most important tasks to a level of satisfactory status before attending to other, less important tasks. For example, continued monitoring of altitude would have a very high value to a pilot while the aircraft is in close proximity to the ground. In fact, the importance of performing this task satisfactorily should most likely take priority over just about any other concurrent task, including a landing gear malfunction task. However, see the example in the beginning of the article.

The Status factor did not show a positive effect in this study. This was unexpected considering its high frequency of reporting in Study 1. We suggest Status is a more significant factor in task prioritization than we reported in this study, the discrepancy being due to several limitations in our methodology. Specifically, the wording of some status-related questions on the questionnaire may have been confusing. For example, to determine if the participants used their perception of whether an ILS tracking task was being performed satisfactorily to set its priority, we asked them to rate their level of agreement with "The reason I tracked the ILS when I did is because 
I judged it to be the task farthest from satisfactory completion." This assertion made no sense to some pilots, for tracking the ILS is not a task "completed" by the pilot's actions so much as it is a task performed until certain conditions are satisfied. We suspect that this wording led to an apparent de-emphasis of the Status factor.

Another unexpected result was the lack of agreement that Urgency is a factor in task prioritization. Because many cockpit tasks are time driven, with hard deadlines, it seems unlikely that Urgency does not influence task prioritization. One potential explanation for this is that the professional pilots that were our participants were so adept at "staying ahead of the airplane" that the conscious perception of Urgency is now rare to them, even though they subconsciously manage activities to meet deadlines.

\section{A HYPOTHETICAL FRAMEWORK AND MODEL OF TASK PRIORITIZATION}

Although our findings may be inadequate grounds for a theory of task prioritization, they at least suggest some hypotheses about how pilots prioritize tasks. We present following a hypothetical framework and a model (Figure 8) of task prioritization. The hypotheses in this framework await confirmation or refutation by further research.

\section{Definitions}

We start with two important definitions.

Priority. Priority is the degree to which a task is believed (rightly or wrongly) to deserve immediate attention based on its role in accomplishing the mission goal to transport passengers and/or cargo from the point of origin to the destination safely and on time.

Task prioritization. Task prioritization is the process by which priorities are subjectively assigned to tasks.

\section{Hypotheses}

The priority of a task at any time depends, in part, on the 6 factors we addressed in Study 2, which were derived from the 12 factors considered in Study 1. Figure 8 shows that these factors tend to increase or decrease a task's priority relative to other tasks in an approach scenario. The length of each arrow in Figure 8 is proportional to the extent that the corresponding factor's influence on task prioritization was supported by the combined findings of Studies 1 and 2 . 


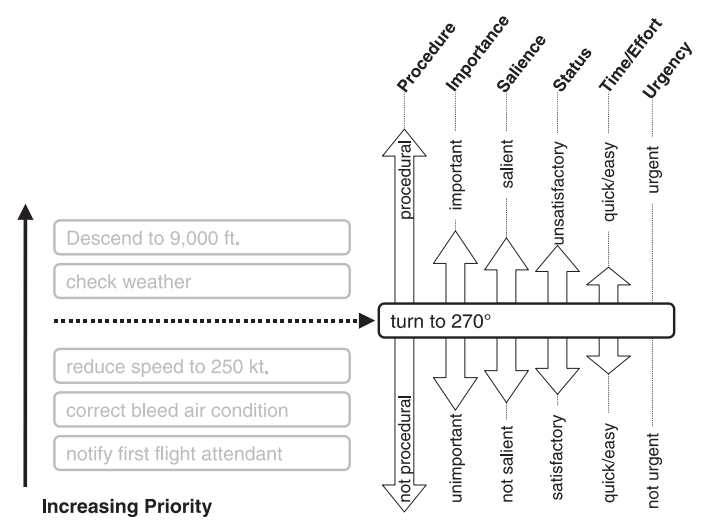

FIGURE 8 A preliminary model of task prioritization showing factors believed to affect the process. Arrow length is proportional to the extent to which the factor is believed to increase or decrease the task's priority based on the results of Study 1 and Study 2.

Hypothesis 1: The priority of a task is directly proportional to its consistency with Procedure or with other pilot expectations.

This factor subsumes the Procedure and Expectancy factors identified in Study 1. A task is consistent with procedure if some formalized procedure specifies that the task be performed in response to some event (e.g., that a published approach procedure calls for a turn to $270^{\circ}$ at a way point, and that way point has been reached). It is consistent with the pilot's expectations if the pilot is otherwise anticipating the need to perform the task in response to some event. In either case, the pilot's memory has been primed to recognize the conditions defining the anticipated event, and if the event has occurred and has been detected, it is appropriate to perform the task. So, if the task is consistent with procedure, its priority is increased, but if the task is not consistent with procedure, its priority is decreased. These results are in agreement with the findings of Adams et al. (1991) and Pashler (1998).

Hypothesis 2: The priority of a task is directly proportional to its Importance.

This factor subsumes the Importance and Consequences factors identified in Study 1 . The importance of a task is the relevance of the task to maintaining safety of flight and accomplishing the mission goal (e.g., flying the published approach path so as to avoid terrain and other traffic and to be properly aligned with the runway for the landing). The importance of a task in this sense tends to increase the task's priority. The undesired consequences of not performing the task properly (e.g., being off the approach path and therefore not properly aligned with the run- 
way) tend to increase the task's priority as well. If a task is less important to safety or the consequences of not performing it well are not serious, its priority is lower.

Hypothesis 3: The priority of a task is directly proportional to its Salience.

We identified this factor in Study 1 and investigated it further in Study 2. Salient stimuli (e.g., the EICAS message "L ENG BLEED VAL" with the accompanying master caution light illumination) tend to raise the priority of related tasks (e.g., "correct bleed air condition"). Particularly intense, large, or otherwise conspicuous stimuli tend to draw attention to related tasks. That is, tasks with salient stimuli tend to receive higher priority than do tasks that have no particularly salient stimuli associated with them.

Hypothesis 4: The priority of a task is inversely proportional to its Status.

This factor subsumes the Status, Rate of Change, Needed Information, and Verifying Information factors we identified in Study 1. The status of a task (e.g., "turn to [heading] $270^{\circ}$ " in Figure 8) is how well it is being performed or how "close" it is to satisfactory performance or successful completion. Closely related to this is the rate of change of a task's status, that is, how rapidly the task is approaching or deviating from satisfactory performance or successful completion. This is particularly significant, at least in our studies, for information acquisition tasks either acquiring or verifying information. Satisfactory task status (e.g., the aircraft's heading is about $270^{\circ}$, or the destination airport's current weather conditions are known) tends to decrease the priority of a task because additional attention to it is not needed to improve performance. Unsatisfactory status (e.g., the heading is, say, $180^{\circ}$, or the current weather conditions are not known) means the task needs attention. If good progress is being made in completing a task (e.g., turning toward $270^{\circ}$ or radio frequency has been set to receive automated terminal information system [ATIS] information), the priority of the task tends to diminish. On the other hand, if poor or no progress is being made (e.g., heading is constant at $230^{\circ}$ or ATIS frequency is not set), its priority increases.

Hypothesis 5: The priority of a task is proportional to the Time/Effort required to perform it.

This factor subsumes the Time/Effort and Resist Forgetting factors we identified in Study 1. If a task is expected to require significant time and effort to accomplish or if considerable effort will be required to remember it if it is not performed soon, the pilot may raise its priority so that it is accomplished quickly. A task requiring little time or effort can presumably be delayed and not interfere too much with upcoming tasks. On the other hand, a quick and easy task may be given a 
higher priority simply to get it done soon and out of the way. For that reason, this factor may have a variable effect on prioritization, depending on individual task management style.

Hypothesis 6: The priority of a task is directly proportional to its Urgency.

We identified this factor in Study 1 and investigated it further in Study 2, and although its influence was negative in Study 2 because it was cited in Study 1 it is retained in the theoretical framework and model. The urgency of a task is the ratio of the time required to complete a task or bring it to a satisfactory level of performance and the time available to do that. The more urgent the task (e.g., "reduce speed to 250 kts." in Figure 8 must be completed by the time the aircraft descends below 10,000 ft.), the higher its priority. If the task is not urgent, its priority is decreased.

\section{SUMMARY, CONCLUSIONS, AND RECOMMENDATIONS}

Our two studies suggest a hypothetical framework and model of task prioritization in which at least six factors are operative: Procedural Consistency of the task, its Importance, the Salience of task-related stimuli, the Time/Effort required to perform the task, and its Urgency.

The framework and model are preliminary, but even in this form, they are potentially useful. For example, they suggest that cockpit procedures could be designed to explicitly address factors that tend to inappropriately affect prioritization. Approach procedures and general operating procedures could be designed to explicitly address nonessential but potentially salient tasks that may tend to interrupt safety-critical tasks. Perhaps pilots should be trained to be aware of factors that impair their ability to prioritize tasks appropriately. Finally, a future, validated theory of task prioritization may be useful in accident investigations to come to a better understanding of conditions and circumstances that led to failures of attention.

Of course, there is cause to question the validity of our findings. Our sample size was small, and although our participants brought a wide variety of flying experience to the experiment, we cannot claim that they were representative of the pilot population as a whole. The participants reported to us their opinions about what factors are active in task prioritization, and although we have no reason to believe that any of them tried to mislead us, we could not verify that these factors were indeed used in actual task prioritization in the experiment, much less in their real flying. In fact, the process of task prioritization may not even be accessible to conscious reflection. We asked the participants questions as if task prioritization were a rational procedure, but it may actually be a very spontaneous process not amenable to the kinds of analysis we applied. Many questions remain unanswered. 
However, despite the small number of participants, they articulated a reasonable set of factors. In spite of limitations in our participants' ability to ascertain and articulate the mechanisms of the task prioritization process, what they reported was largely consistent with our earlier studies and the literature. Task prioritization may be a spontaneous process in many cases, but in others, there seems clear and conscious rationality in task prioritization decisions. In any case, what our participants reported is the best information we have so far, and this information is valuable for posing testable hypotheses about the true factors.

We recommend that additional studies be conducted to test these hypotheses. If the cited factors are found to truly affect task prioritization, the direction and magnitude of that effect should be investigated. Task prioritization procedures and task prioritization training should be developed and tested.

There is reason to believe that task management, and therefore task prioritization, are significant to flight safety. It is important that we build our knowledge of the nature and significance of these processes and develop ways to improve them.

\section{ACKNOWLEDGMENTS}

This research was completed under NASA Ames Research Center Grant NAG 2-1287, Training Pilots to Prioritize Tasks. We gratefully acknowledge NASA's support and, especially, the encouragement and advice given by our technical monitor, Key Dismukes.

\section{REFERENCES}

Adams, J. J., \& Pew, R. W. (1990). Situational awareness in the commercial aircraft cockpit: A cognitive perspective. In IEEE 9th Digital Avionics Systems Conference (pp. 519-524). New York: Institute of Electrical and Electronics Engineers (IEEE).

Adams, M. J., Tenny, Y. J., \& Pew, R. W. (1991). State-of-the-art report: Strategic workload and the cognitive management of advanced multi-task systems (SOAR CSERIAC 91-6). Wright-Patterson Air Force Base, OH: Crew System Ergonomics Information Analysis Center.

Chou, C. D., Madhavan, D., \& Funk, K. F. (1996). Studies of cockpit task management errors. The International Journal of Aviation Psychology, 6, 307-320.

Colvin, K. W. (2000). Factors that affect task prioritization on the flight deck. Unpublished doctoral dissertation, Oregon State University, Corvallis.

Cooke, N. J. (1994). Varieties of knowledge elicitation techniques. International Journal of Human-Computer Studies, 41, 801-849.

Fisher, R. P., \& Geiselman, R. E. (1992). Memory-enhancing techniques for investigative interviewing: The cognitive interview. Springfield, IL: Thomas.

Funk, K. H. (1991). Cockpit task management: Preliminary definitions, normative theory, error taxonomy, and design recommendations. The International Journal of Aviation Psychology, 1, 271-285.

Gopher, D. (1992). The skill of attentional control: Acquisition and execution of attention strategies. In D. E. Meyer \& S. Kornblum (Eds.), Attention and Performance 14: Synergies in experimental psy- 
chology, artificial intelligence, and cognitive neuroscience (pp. 124-179). Cambridge, MA: MIT Press.

Logan, G. D. (1985). Executive control of thought and action. Acta Psychologica, 60, 193-210.

National Transportation Safety Board. (1973). Aircraft accident report. Eastern Airlines, Inc., L-1011, N310EA, Miami, Florida, December 29, 1972 (Tech. Rep. No. NTSB-AAR73-14). Washington, DC: Author.

Pashler, H. E. (1998). The psychology of attention. Cambridge, MA: MIT Press.

Salter, W. J. (1988). Human factors in knowledge acquisition. In M. Helander (Ed.), Handbook of human-computer interaction (pp. 234-292). Amsterdam: Elsevier.

Schutte, P. C., \& Trujillo, A. C. (1996). Flight crew task management in non-normal situations. In Proceedings of the Human Factors and Ergonomics Society 40th annual meeting (pp. 244-238). Santa Monica, CA: Human Factors and Ergonomics Society.

Manuscript First Received: May 2002 